\title{
Max Weber (1864-1920): denker over godsdienst en kapitalisme
}

\author{
Hans Ester \\ Nijmegen \\ Nederland \\ E-pos: j.ester@let.ru.nl
}

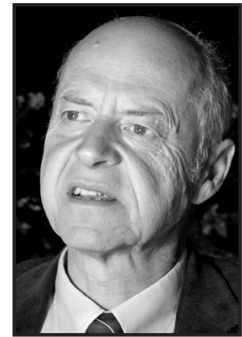

Hans Ester

HANS ESTER (1946) groei op in Utrecht (Nederland) en Bielefeld (Duitsland). Na Hoër Skool studeer hy Duits, Teologie en Afrikaans in Amsterdam, Tübingen en Johannesburg. Hy promoveer in 1975 in Leiden en ontvang 'n eredoktorsgraad van die Noordwes-Universiteit (Potchefstroom) in 2000. Na twee jaar as onderwyser in Utrecht doseer hy Duitse letterkunde en kultuurwetenskap aan die Radboud Universiteit Nijmegen. In 1995 is hy gasdosent by Rhodes University in Grahamstad. Tans is Hans Ester redakteur van die jaarboek Deutsche Chronik en sekretaris van die Stigting "Kunstenaarzverzet 1942-1945". Hy het boeke gepubliseer oor Theodor Fontane, Elisabeth Eybers, NP van Wyk Louw, Berlyn, Goethe, Oostenrykse letterkunde, Switserse letterkunde, vertaalwetenskap en Duits-Nederlandse verhoudings. Sy mees resente boekpublikasie, met Chris van der Merwe as mederedakteur, is Twyfelaars wat glo (Stellenbosch 2019). In 2021 verskyn Verbotene Bücher in samewerking met Barbara Mariacher. In 2022 volg 'n studie oor Franz Werfel en die moord op die Armeniërs.

Na een enkele alinea van de Duitse geleerde Max Weber gelezen te hebben, weet iedereen dat Weber een fenomenale denker was. De onderwerpen die hij aansnijdt, zijn verrassend en de strategie van argumenteren is boeiend en veeleisend. Wie hierin mee wil denken, moet in de eerste plaats goed kunnen luisteren. Naar wie luisteren we wanneer vandaag over Weber wordt gesproken? Zoals in veel andere gevallen gebeurt, hebben wij in beschrijvingen van zijn ideeën met Max Weber in gereduceerde vorm te maken. De theoloog Ulrich Ruh uit het Duitse Freiburg wees in zijn proefschrift Säkularisierung als Interpretationskategorie. Zur Bedeutung des christlichen Erbes in der modernen Geistesgeschichte uit 1980 al op de vernauwde visie op Max Weber in publicaties over hem. Ook de cultuurfilosoof HW von der Dunk wijst in zijn boek De verdwijnende hemel. Over de cultuur van Europa in de twintigste eeuw, deel 1 (Amsterdam, 2000) op de geringe, eenzijdige acceptatie van Webers werk in vergelijking met dat van Karl Marx en Sigmund Freud. Zeer veel publicaties zagen de afgelopen honderd jaar het licht over die ingrijpende ontwikkeling binnen de Westerse cultuur die "secularisatie" of "secularisering" heet. Steevast komt Weber als de vader van het secularisatie-onderzoek in 
beeld. Dat is niet geheel terecht en evenmin volkomen onterecht. De suggestie dat alles bij Weber om het begrip "Säkularisierung” draait, heeft in ieder geval krachtige nuancering nodig. In Webers onderzoek naar de geest van het kapitalisme en zijn religieuze wortels is het protestantisme één van de bepalende bestanddelen van de moderne kapitalistische geest. Nergens gaat Weber versimpelend te werk, zodat we geenszins met een korte bondige samenvatting van zijn werk in de vorm van een stelling zouden kunnen volstaan. Zelfs Webers opvatting dat er een bepaalde verhouding is tussen zekere richtingen (het puritanisme, het calvinisme) binnen het protestantisme en de geest van het kapitalisme is zo ingekrompen dat de oorspronkelijke betekenis is aangetast. Weber verlangt meedenken en nuancering, geen gemakzuchtig uittreksel. De Nederlandse filosoof en socioloog AJ Nijk had al voordat Ruh dat deed op deze vertekening gewezen in zijn schitterende dissertatie Secularisatie. Het gebruik van een woord uit 1968. Nijk zegt daarin over het gebruik van "secularisering" en "secularisatie" bij Weber: "Waar de termen voorkomen maken zij de indruk argeloos gebruik te zijn; hun betekenis kan wisselen en wordt niet scherp omlijnd. Dat is veelzeggend bij een auteur die zich in hetzelfde werk [over economie en samenleving] zo uitermate veel moeite heeft getroost tot methodische en vooral ook tot terminologische helderheid te geraken" (Nijk 1968:30). Met het noemen van de terminologische helderheid bij Weber heeft Nijk helemaal gelijk. Het afleggen van verantwoording over alles wat je als mens in het leven doet, was Max Weber met de paplepel ingegoten. Zijn vader was een telg uit een geslacht van textielfabrikanten uit het tot Pruisen behorende Bielefeld in Westfalen. Zijn moeder was van Hugenoten-afkomst. Max Weber senior was een en al correctheid, als jurist en als politicus in Berlijn. Het geloof zei hem niet veel. Helene Weber had in tegenstelling tot haar man een diep innerlijk geloof dat haar geestelijke oriëntatie volledig bepaalde. Zelfs haar opvatting van de geslachtsgemeenschap als zondige handeling die slechts aanvaardbaar was met het oog op het voortbrengen van nageslacht was een uitvloeisel van haar geloof. Zij probeerde dit piëtistische geloof op haar oudste zoon over te dragen, maar dat gelukte slechts tijdelijk. Max Weber hield zich wel zijn hele leven met geloof en religie bezig, maar eerder vanuit vragen naar de relatie tussen geloof, zingeving en sociaal-politieke ontwikkelingen dan vanuit een persoonlijke beleving van de geloofsinhoud.

Max Weber (1864-1920) studeerde rechtsgeleerdheid in Heidelberg en voegde daar later in Berlijn staatshuishoudkunde/algemene economie aan toe. Hij promoveerde in 1889 op een proefschrift over de oorsprong van handelsmaatschappijen in de rechtspraktijk van middeleeuwse steden in Italië en schreef zijn habilitatiegeschrift (de voorwaarde voor het professoraat in Duitsland) over de naar een vorm van kapitalisme leidende agrarische geschiedenis der Romeinen. Max Weber heeft over zoveel onderwerpen van cultuurhistorische, sociologische, theologische en economische aard zo fundamenteel en gewapend met enorme kennis onder andere in Freiburg en Heidelberg college gegeven en gepubliceerd dat het niet verbaast dat hij in 1898 volledig instortte en pas na jaren weer tot grote intellectuele arbeid in staat was. Webers biograaf Dirk Kaesler suggereert dat er een mogelijk samenhang is van de diepe breuk die in 1897 tussen Max Weber junior en zijn vader Max Weber senior ontstaat en zijn psychische en lichamelijke ontreddering. In zijn boek de met enigszins gechargeerde titel Max Weber. Preusse, Denker, Muttersohn laat Dirk Kaesler Webers vrouw Marianne aan het woord die een indringend beeld geeft van de crisis waarin haar man in 1898 verkeert: "Letterlijk alles is hem te veel: lezen en schrijven is een marteling. Hetzelfde geldt voor praten, lopen en slapen. Alle psychische en een deel van de lichamelijke functies weigeren dienst. Als hij hen desondanks tot gehoorzaamheid dwingt, dan bedreigt hem de chaos, een gevoel alsof hij in de draaikolk van een nerveuze toestand kan geraken die de geest verduistert" 
(Kaesler 2014: 475). De woede jegens zijn vader tijdens een ouderlijk bezoek vanuit Berlijn aan de kinderen in Heidelberg is gedeeltelijk te verklaren vanuit Max Wevers vereenzelviging met zijn moeder Helene. Zijn uiterst vrome moeder had weinig ruimte voor zichzelf binnen het strenge regime van de vader. Vader en zoon eisten beide de moeder op.

Door de brede waaier van onderwerpen waar Max Weber zich mee bezig hield, is het lastig om hem bij een wetenschappelijke discipline in te delen. Het zou tegen de geest van zijn werk indruisen, wanneer wij hem als socioloog, godsdienstsocioloog, econoom, filosoof of cultuurwetenschapper zouden classificeren. Van de breedte van interessegebieden en onderzoeksvelden getuigt de uitgebreide vriendenkring in Heidelberg. Deze kring die wekelijks bijeenkwam om naar een lezing te luisteren en daarover te discussiëren omvatte grote geesten op velerlei gebied. Werner Sombart, Ernst Troeltsch, Georg Simmel, Edgar Jaffé, Else von Richthofen, Heinrich Rickert zijn slechts enkelen van de deelnemers. Kaesler laat in zijn biografie zien dat Max Weber de uitdaging van afwijkende meningen en van hardop denken en tastend formuleren nodig had om nieuwe perspectieven op de menselijke samenleving in heden en verleden te zien. De uitwisseling bleek uitermate vruchtbaar te zijn, al hoorde Weber het liefst zichzelf praten en kon hij ironisch en sarcastisch uit de hoek komen. Het schrijven van brieven was voor Weber eveneens een levensnoodzaak. Brieven waren een middel tot uitwisseling van sociaal nieuws, maar meer nog een probaat middel om helderheid over de eigen standpunten te krijgen en zich geestelijk te verrijken door de dialoog met de briefpartner van hetzelfde niveau die bevestigde en ter discussie stelde. Het duidelijkst wordt het werk van Max Weber in zijn karakter als vrucht van de uitwisseling door de vergelijking met de geschriften van zijn vriend Ernst Troeltsch (1865-1923). Bij het verklaren van de maatschappelijke, economische en religieuze ontwikkelingen duiken bij Troeltsch eveneens begrippen op als "rationalisatie", "de betekenis van het protestantisme voor het ontstaan van de moderne wereld", "het Lutherdom", "het individuele en het algemene" en "de zin van de geschiedenis".

Als geschiedkundige, als wetenschapstheoreticus, als cultuurbeschouwer en als socioloog was Weber al in zijn eigen tijd een prominent denker. Van alle kanten kreeg hij impulsen om mee te denken. Vooral was hij een vernieuwend denker die in staat was zijn eigen vooroordelen en vooronderstellingen waar te nemen en de schaduw van zijn eigen redeneringen zichtbaar te maken. Het denkpatroon van Max Weber is gericht op het plaatsen van vraagtekens achter iedere stap die hij zet.

De eerste hobbel waarmee de lezer van Webers werk te maken krijgt, is de taal. Als voorbeeld van zijn lastige taal haal ik een gedeelte uit Webers opstel "Het beursverkeer" uit 1896 aan. Hij schreef deze brochure voor zijn vriend, de predikant en maatschappijcriticus Friedrich Naumann als reactie op het "Genootschap voor ethische cultuur" en haar tijdschrift "Ethische cultuur". Het gaat om de vraag naar de mogelijkheden van ethisch handelen in de reële wereld: "Aan het in praktijk brengen van zuiver theoretisch-morele eisen zijn nu eenmaal, zo lang de naties, ook wanneer ze militair gezien in vrede met elkaar leven, economisch de onverbiddelijke en onvermijdelijke strijd om hun bestaan als natie en om de economische macht voeren, nauwe grenzen getrokken door de overweging, dat men ook economisch niet eenzijdig kan ontwapenen. De kapitaalreserves van de grote banken zijn in net zo geringe mate liefdadige instellingen als geweren en kanonnen dat zijn." Wanneer de Nederlandse tekst moeilijk te begrijpen is, dan geldt dat nog veel meer voor Webers oorspronkelijke Duits. Tot de meest opvallende stijlverschijnselen van Webers taal hoort de tussenzin. In tussenzinnen worden aanvullende argumenten gegeven. De tussenzinnen lopen ook vooruit op mogelijke 
tegenwerpingen. De vergelijkingen - in dit geval van het kapitaal van banken met geweren en kanonnen - zijn argumenten die gevoed worden door de macht van de humor.

Om iets van zijn werk te begrijpen, luidt het devies voor de lezer anno 2021 dat je de tijd moet nemen en de zinnen vaak hardop moet uitspreken om te weten welk onderwerp bij welk gezegde hoort, waarom er een tweede naamval in een zin voorkomt en wat de (energie sparende) functie is van een niet ingeleid woord waarmee een bijzin begint. Een voorbeeld daarvan opening van bijzin met de uitdrukking "Gedankenfreiheit" - zien we in een reactie op Naumanns ontwerp van het programma van de nieuwe politieke partij: "Wat wilt u nu eigenlijk? Wil men in een nationale arbeiderspartij die opklimmende klassen der arbeiders voor zich trachten te winnen, zou dat zonder twijfel een vooruitgang zijn. Het zou de geestelijke emancipatie van de arbeiders betekenen, vrijheid van denken, die de sociaaldemocratie niet toestaat, doordat ze het in gruzelementen liggende systeem van Karl Marx als dogma in de hoofden van de massa stempelt." De geestelijke emancipatie der arbeiders uit zich dus in de vrijheid van denken. De stilistisch geslaagde tegenstelling schuilt in "vrijheid van denken" tegenover het mechanische "stempelen". Dat Weber het lot van de arbeiders na aan het hart lag, blijkt wel uit de grote enquète die hij als prille onderzoeker samen met de predikant Paul Göhre in 1892 onder landarbeiders in Pruisen hield en uit de voor de Pruisische grootgrondbezitters negatieve gevolgtrekkingen uit deze enquète. De enquèteurs waren de "Dorfpfarrer", de dorpsdominees. De opdrachtgever was de "Verein für Socialpolitik". Het resultaat was een helder beeld van de variabele behoefte aan arbeidskrachten op de grote landgoederen gedurende het jaar, van de verschillen in bodemgebruik en ten aanzien van de productietechnieken. De enquète leidde tot conclusies over de richting der ontwikkelingen en had zowel een sterk sociologisch als economisch karakter. De enquète signaleerde het gevaar dat de provincies ten oosten van de Elbe hun Duitse landarbeiders zouden verliezen en dat Poolse seizoenarbeiders hun plaats zouden innemen.

Globaal gezien domineren vier grote thema's in Webers werk. Het gaat daarbij in de eerste plaats om het zoeken naar het verband tussen religieuze basisvoorstellingen en de normen van het economische leven van alledag. Tot de religieuze basisprincipes behoort de keuze om van het persoonlijke bezit niet onbevangen te genieten, maar het genot te vermijden door ascese, dus door zich van het genieten te onthouden. Het centrale werk waarin Weber zijn gedachten ontplooit, is Die protestantische Ethik und der Geist des Kapitalismus uit 1906. Dit werk bezorgde Weber in zijn tijd grote faam en werd door menigeen, zonder scrupules, in enkele zinnen samengevat. Alsof het calvinisme als camouflage van roofzucht fungeerde. Weber is zo behoedzaam in het vastleggen van cruciale gedachten en begrippen dat zijn betoog pas na geduldig peilen van de gehanteerde termen steeds een stapje verder komt. Wat Weber bijzonder maakt, is de veelheid van verschijnselen die hij aan zijn onderzoek ten grondslag legt. Hij bestudeert de cultuur in al haar aspecten en probeert zicht te krijgen op de werkzame factoren binnen de cultuurgeschiedenis. Daarom wijst hij simpele causale, op oorzaak en gevolg gestoelde eendimensionale verklaringen van belangrijke ontwikkelingen af. Weber wil verbanden laten zien en heeft bij zijn bevindingen altijd oog voor de complexiteit van sociaalculturele gegevens, vooral wanneer het om het verband van samenleving en godsdienst gaat. Een Europese kijk op godsdienst verrijkt hij door naar andere wereldgodsdiensten te kijken. Het heden relativeert hij door naar de oude geschiedenis van Griekenland en de Aziatische culturen, vooral die van het oude China, terug te gaan.

In zijn Die protestantische Ethik begint Weber met de vraag naar de omstandigheden die er toe hebben geleid dat in het als Avondland betitelde Europa, heel in het bijzonder in het Westen en Midden van Europa, unieke culturele verschijnselen optraden waarvan de dynamiek 
universele betekenis en geldigheid verkreeg. Weber bedoelt de wereldomvattende betekenis van het kapitalisme, terwijl zich er in dit beginstadium van zijn onderzoek terdege van bewust is dat hij het begrip kapitalisme eerst zou moeten definiëren. Die definitie is lastig, omdat over de hele wereld met geld handel wordt gedreven met het oogmerk van winst, van vergroting van het beschikbare bezit. Het streven naar geld wordt "kapitalisme" genoemd. Voor Weber is deze begripsomschrijving onvoldoende, omdat die niet precies genoeg is om de ontwikkeling op het gebied van kapitaalvermeerdering in het Avondland goed weer te geven.

Weber wil de universele ontwikkeling van het kapitalisme afleiden uit de specifieke ontwikkeling in het genoemde Avondland. In een eerste benadering tot specificatie noemt hij als bijzonderheden: de bedrijfsorganisaties (te denken is aan de gilden), de scheiding van huishouden en bedrijf, het technische gebruik van wetenschappelijke inzichten voor de "Lebensordnung" (leefstructuur) van de arbeidende massa's door economische premies en het voeren van een bedrijfsboekhouding.

Welke bestanddelen van de sociale ordening hebben het moderne kapitalisme op gang gebracht? Als eerste bestanddeel noemt Weber de formele regels van het recht. Het moderne bedrijfskapitalisme heeft voor een rationeel functionerende bedrijfsvoering een calculeerbaar recht en een calculeerbare administratie nodig. Op beide voorzieningen, resp. regelingen moet je kunnen vertrouwen. Anders zou het een kapitalisme van speculerende avonturiers, egoïstische beursspeculanten zijn. Dit moderne kapitalisme heeft een veilige en zekere rekenbasis nodig om te kunnen functioneren en in de tijd vooruit te kunnen kijken.

Weber erkent met het begrip "sociale ordening" de fundamentele betekenis van het rationalisme van het Avondland. De economische voorwaarden zijn bepalend voor de verdere ontwikkeling. Maar, het economisch rationalisme is in het proces van zijn ontstaan ook van de bekwaamheid en de toewijding van de mensen aan bepaalde praktisch-rationele leefwijzen afhankelijk. Tot de belangrijkste vormende elementen van de leefwijze behoorden volgens Weber in het verleden bepaalde magische en religieuze machten en de in het geloof aan deze machten verankerde ethische opvattingen in de zin van plichten. Uit dit verband van economisch handelen en religie/geloof vloeit het centrale probleem van Webers studie voort. Hij beoogt de voorwaarden van het ontstaan van een "Wirtschaftsordnung", een bepaalde geestelijke ingesteldheid ten opzichte van het economisch leven, aan te tonen door deze te koppelen aan religieuze geloofsinhouden. Preciezer geformuleerd: Weber wil de samenhang aantonen van het moderne economische ethos met de traditionele ethiek van het ascetische protestantisme.

Hoe kunnen de aan godsdienstige onderwerpen toegewijde, ernstige en wereldvreemde calvinisten zulke invloedrijke ondernemers zijn? Is er geen tegenstelling tussen wereldvreemdheid, ascese, onthouding van genot en kerkelijk gebonden vroomheid enerzijds en deelname aan het kapitalistische beroepsleven anderzijds? Uit de pastorie komen immers kapitalistische ondernemingen van grote allure voort en heerst er onder calvinisten een "virtuoze kapitalistische ondernemersgeest" (citaat van Weber). In het kader van zijn antwoord plaatst Weber de ethiek en bovenal: de ethische waarde van arbeid en beroep, in het middelpunt van zijn beschouwingen. Het doel van het leven is het verwerven van geld en goederen, niet met het oog op onbevangen genieten van het verworvene. De mens heeft een verplichting tegenover de inhoud van zijn activiteit. Te denken is aan arbeidsdiscipline en aan de beroepsplicht tegenover de groep waartoe men behoort. Het beroep is een taak die God de mens heeft opgelegd. Bij Maarten Luther had het beroep reeds hoogstaande betekenis gekregen. De meest fundamentele ethische basis van de wereldlijke beroepen is respect voor de vervulling van de plicht. De plicht vervullen is het enige middel om God welgevallig te leven. Het beroep is rechtstreeks verbonden met God's bedoeling met de wereld. Het grote vraagstuk waarmee de 
gelovige puriteinen en calvinisten worstelden, gold de verlossing van de mens. Het door Calvijn onbetwiste gegeven dat slechts een klein deel der mensheid tot eeuwige zaligheid was uitverkoren diende de bevestiging van God's majesteit. Hier zijn arbeid en beroep van doorslaggevend belang. Ter meerdere glorie van God dient de mens in overeenstemming met God's geboden het leven, inclusief het sociale leven, zo gestalte te geven dat deze arbeid beantwoordt aan het ultieme doel. Dat doel luidt: de vermeerdering van God's glorie op aarde.

Arbeid is het geëigende middel voor de ascese. Arbeid is het preventiemiddel bij uitstek tegen alle aanvechtingen vanuit het leven die God niet welgevallig zijn. Een beroep ter verrichting van arbeid is een instelling van God en een strikte opdracht van God, opdat de afzonderlijke mens te Zijner ere werkzaam zou zijn. De ascese vindt in de wereld plaats. De ascese is het wapen tegen het onbevangen genieten van bezit. En de ascese legitimeert het streven naar winst en beschouwt dit streven als uitvloeisel van God's wil.

Door de religieuze lading van de arbeid, van het beroep als roeping, kreeg het verwerven van goederen derhalve een religieuze legitimering. De arbeid was door God gewild. Rusteloos, constant werken was de invulling van een ascetische levensopvatting. Tevens, zo zegt Weber, was het door God gewilde werken de proef op de som van de wedergeboren mens en van de echtheid van zijn geloof. Enerzijds wordt binnen deze inkadering de consumptie van het verworvene ingesnoerd, anderzijds wordt het streven om goederen te verwerven en kapitaal te vermeerderen vrijgemaakt, als het ware ontketend. Zo ontstaat de hefboom van die expansie die we de "geest van het kapitalisme" noemen, aldus Weber. Hiermee is de ontwikkeling nog niet voltooid. Deze ontwikkeling leidt naar een andere vorm van kapitalisme. De puriteinse levensopvatting stond volgens Weber aan de wieg van de moderne "Wirtschaftsmensch", de mens in zijn economische wijze en keuze van handelen. Bepalend is na de ontwikkeling van de genoemde hefboom de emancipatie van het economisch handelen van zijn religieuze oorsprong. Daarom zegt Weber dat de religieuze bewegingen hun volle economische effect pas realiseerden nadat het koortsachtig hoogtepunt van het zuiver religieuze enthousiasme overschreden was, nadat de krampachtige zoektocht naar het Rijk Gods allengs begon over te gaan in nuchtere deugdzaamheid aangaande de beroepsuitoefening. Weber: "De religieuze wortel stierf langzaam af en maakte plaats voor een op het hier en nu gerichte nuttigheidsopvatting." De geïsoleerde economische mens, die "en passant aan zending doet" neemt de plaats in van de eenzame, naar het Hemelrijk strevende pelgrim van John Bunyan. Uiterst scherp formuleert Weber het als volgt: "Het goede geweten moest tenslotte simpelweg opgenomen worden in de reeks middelen die het comfortabele burgerlijke leven vormen." Het burgerlijke beroepsethos omvat het bewustzijn dat de mens deel heeft aan Gods volle genade en dat deze burger door God op zichtbare wijze gezegend is, alles gekoppeld aan de rustgevende overtuiging dat de ongelijke verdeling der goederen van deze aarde het werk van Gods voorzienigheid vormt. Deze verschillen in verdeling dienen een doel dat ons mensen onbekend is. Daar berusten wij in. Het bleef niet bij de analyse van het christendom in relatie tot arbeidsethos en kapitaalvorming. Weber maakte een belangrijk begin met zijn studie naar de effecten op de samenleving van Oosterse godsdiensten en bestudeerde het Jodendom nauwkeurig. Deze studies kon hij niet meer afmaken. In tegenstelling tot collega's als Heinrich von Treitschke is bij Weber geen spoor van antisemitisme te ontdekken. Integendeel! Terugkijkend op de voor Weber typerende combinatie van economie, sociologie en cultuurwetenschap zou de conclusie kunnen luiden dat hij gepredestineerd was voor de marxistische visie op de rol van de arbeider in de geschiedenis. Het zou op het eerste gezicht niet onlogisch zijn geweest, wanneer Weber de gedachten van Marx over het primaat van de eigendomsverhoudingen met betrekking tot de productiemiddelen en over de vormen van de productie 
zou hebben overgenomen. En toch was dat op de keper beschouwd wel degelijk onlogisch en onmogelijk. Weber zag namelijk dat de zogeheten "bovenbouw" een grote zelfstandige kracht was binnen de economische ontwikkeling en dat een religieuze belijdenis en een juridische regel de oorzaak konden zijn van complexe ontwikkelingen op het gebied van kapitaal en arbeid. Een vergelijking met Marx is hier inzichtgevend. Ook Marx onderkent een zekere zelfstandigheid van de "bovenbouw", maar eerder als een soort achteropgeraakt, verkeerd denken. Bij Weber is de godsdienst een kracht met een zelfstandige waarde. Weber was voortdurend bezig met vragen over de historische beginfase van het moderne, rationele bedrijfskapitalisme. Hij wilde weten hoe het tot dit rationaliseringsproces in West-Europa gekomen was. Tastend antwoord geven kon alleen maar vanuit meerdere perspectieven via een interdisciplinaire beschouwing van de vraag.

Max Weber gaf zelf toe dat aan zijn visie op de ontwikkeling van de geest van het kapitalisme allerlei haken en ogen zaten. Methodisch gezien was de grote vraag, op welke feitelijke informatie hij zich kon beroepen om aan te tonen dat deze overgang op de geschetste manier plaatsvond. Waren de geraadpleegde getuigenissen solide genoeg om daaruit zulke verstrekkende conclusies te trekken? Was de uitleg van de invloedrijke geloofsvormen juist?

Ook voor het tweede grote thema - de methode van wetenschappelijk onderzoek - gold het gevaar van versimpeling door de gebruikers na Weber. Weber vroeg zich af hoe het mogelijk was om ten aanzien van een veelheid aan feiten zodanig te werk te gaan dat de betekenisvolle feiten op zouden lichten en als belangrijk voor het inzicht in een bepaalde ontwikkeling kenbaar zouden worden. Een dergelijke ontwikkeling is bijvoorbeeld het ontstaan van de geest van het kapitalisme. Ten dienste van het inzicht in betekenisvolle ontwikkelingen presenteerde Weber zijn gedachten over de "Idealtypen". Een dergelijk "Idealtypus" is niet bedoeld als voorgegeven weg, als methode naar een te kennen doel en evenmin als hypothese. Het "Idealtypus" is een richtingwijzer onder voorbehoud. Het leidt naar mogelijkheden om bepaalde empirische gegevens te ordenen, waarbij de ordening beoordeeld wordt op grond van de kennis en inzichten die zij mogelijk maakt. Dit alles onder het overkoepelende uitgangspunt dat het om mogelijke strategieën van ordening en zinvolle groepering van zinloze hoeveelheden gaat. Om een voorbeeld te geven: uit een ongeordende veelheid van gegevens over een specifieke menselijke samenleving zou het "Idealbild" van de bureaucratisch geleide staat de zinvolle verbanden tussen die chaos van gegevens kunnen blootleggen. Mij lijkt dit ook mogelijk te zijn bij het hanteren van periodebegrippen die een veelheid van informatie tot wezenlijke kenmerken van een zekere tijdsperiode proberen terug te brengen. Binnen de cultuurgeschiedschrijving gaat dit zeer vaak mis en wordt de veelheid aan verschijnselen aan de eenvoud van de schijn van één centraal kenmerk opgeofferd. De Romantiek is daar een prominent slachtoffer van. Wat draagt daarentegen bij het onderzoek naar een periode als de Barok het gebruik van het "Idealtypus" "theatraliteit" bij? Hoe beschermt dit "Idealtypus" zich tegen versimpeling? Ik laat het bij een vraag.

Als derde belangrijke onderwerp binnen het palet aan onderzoeksvragen van Max Weber denk ik aan zijn bezinning op de aard van de wetenschap en de rol van de persoon van de wetenschapper. Dan gaat het om de innerlijke roeping om wetenschapper te zijn, om intellectuele rechtschapenheid en onvoorwaardelijke objectiviteit. In het kader van de vraag naar integriteit en objectiviteit van de wetenschapper is Webers spreken over waardevrijheid en waardeoordeels-vrijheid van de wetenschappelijke activiteit ten prooi gevallen aan misverstanden. In geen geval gaat het om een pleidooi voor een puur empirische wetenschap. In dit verband is de terugvertaling van Webers gedachten naar de discussies over geesteswetenschap en natuurwetenschap aan het einde van de negentiende eeuw noodzakelijk. 
Kaesler wijst daar in zijn biografie op (Kaesler 2014: 560). Weber loopt met zijn gedachten over de schaduw van de wetenschapper en zijn gebruik van de begrippen "Erkenntnisinteresse" en "Wertinteresse"doelend op de subjectieve keuzes die iedere onderzoeker vooraf maakt, vooruit op gedachten van Jürgen Habermas.

Voor de drie genoemde thema's als mede voor Webers vierde hoofdthema, de opvatting van de politiek als beroep geldt dat simpele eenduidigheid bij hem niet voorkomt.

Is de betekenis van Webers opvattingen door ons volledig te peilen of vervallen we onwillekeurig in een stramien dat zijn grondgedachten weerspreekt? Wanneer we ons tot het werk beperken, is het mogelijk dat we het reliëf van de door Weber gebruikte woorden niet waarnemen. Daar is maar een remedie tegen: terugplaatsen van Max Weber in de context van de decennia voor en na 1900, vanzelfsprekend voor zover ons dat mogelijk is. Deze opvatting vertegenwoordigt Dirk Kaesler in zijn biografie over Max Weber. Het gevolg hiervan is dat Webers opvattingen als resultaat van een permanent gesprek met zijn tijdgenoten meer betekenis krijgen. Webers ideeën over de relatie tussen het protestantisme en de geest van het kapitalisme zijn geen vrijblijvende gedachten maar betrokken standpunten over de ontwikkelingen binnen de samenleving ten aanzien van de concentratie van kapitaal, de aandelenmarkt, de rol van de adel in Pruisen, de inhoud van de democratie, de rol van de Derde Stand (de burger) de processen van rationalisering en bureaucratisering. Kaesler is waarschijnlijk de beste kenner van dit moment van Webers werk. Hij ziet ook twijfels bij Weber, het zwenken van de ene mening naar de andere en hij onderkent de rol van heftige emoties in Webers oordelen. Weber leefde van de veelheid aan impulsen en polemieken die zijn academische bestaan bepaalde. Het is uiterst lastig om uit zijn werk een aantal onaantastbare waarheden te destilleren. Hij had het christelijk geloof verloren en toch is dat geloof in bepaalde standpunten weer levend aanwezig. Hij was afkomstig uit de gegoede burgerij en had nochtans tot op zekere hoogte gevoel voor de levensomstandigheden van de arbeiders. Hij zag de nadelen van de aandelenbeurs, de termijnhandel en de accumulatie van kapitaal bij individuen en banken en achtte deze hoeders van de orde van het kapitaal toch acceptabel en zelfs onmisbaar. Hij was liberaal, maar dacht in de eerste plaats vanuit het nationale belang van de Duitse natie. Allesoverheersend is naast en boven deze combinaties van tegengestelde posities het gegeven dat Weber de dialoog opzocht, vooral met mensen van wie hij vermoedde dat ze meer wisten dan hij.

Wanneer de lezer de moeilijkheden van Webers taal overwonnen heeft, is de actualiteit van diens vragen en constateringen frappant. Op de momenten waarop de lezer overrompeld wordt door de geweldige kracht en de juistheid van een inzicht of vraag, is het zaak om de vertaling naar de context te verwezenlijken.

In Kaeslers biografie staat een groot hoofdstuk over de reis die Max en Marianne Weber naar Amerika maakten. Ook de filosoof Ernst Troeltsch was van de partij. Het doel was een wetenschappelijke conferentie tijdens de wereldtentoonstelling in St. Louis in 1904. De Webers maakten er een maandenlange rondreis van. Max Weber was in tegenstelling tot Ernst Troeltsch en vele andere Duitsers uit die tijd gefascineerd door de moderniteit van Amerika. Ook voor zijn verduidelijking van de moderniteit van de Amerikaanse samenleving en haar economische organisatie grijpt Weber terug op het verband van godsdienst en arbeidsethos. De reis was een uitdaging om de ontwikkelingen in Amerika met die in Europa te vergelijken en vanuit het "Idealtypus" van de door en door georganiseerde staat een visie op de toekomst te ontwikkelen.

Zonder Amerika zou Max Weber niet de gezondheid hebben herkregen die hem in staat stelde om nadat hij in Heidelberg afscheid had genomen in München en Wenen te doceren. Hij moet een bevlogen en inspirerende docent zijn geweest. Tijdens zijn colleges en lezingen zette hij zichzelf in. Van zijn teksten gaat nog altijd een bijzondere, aansprekende kracht uit. 
Die reikt verder dan het gevoel dat je even achter de schermen van een vervlogen eeuw kijkt. Hij draagt iets wezenlijks bij aan de heldere en goede manier van denken. En Weber zegt iets over ons nu, als christenen die vooral burgers zijn. Honderd vijftig jaar geleden werd hij geboren.

De literatuur over Max Weber is nauwelijks nog te overzien. Dirk Kaesler noemt de voornaamste publicaties aan het slot van zijn biografie.

Het proefschrift van Ulrich Ruh verscheen in 1980 bij Herder-Verlag in Freiburg im Breisgau. Ook na dit proefschrift heeft Ruh veel over het verschijnsel "secularisatie" gepubliceerd. De omvattende studie van HW von der Dunk verscheen in 2000 bij uitgeverij Meulenhoff in Amsterdam. De dissertatie van AJ Nijk kwam uit bij Lemniscaat in Rotterdam in een door J. Sperna Weiland geredigeerde reeks.

Kaesler, Dirk. 2014. Max Weber. Preusse, Denker, Muttersohn. Eine Biographie. München:Verlag C H Beck. (1007 blz., gebonden, met foto's, prijs $€ 38$,=).

Weber, Max. 1969. Die protestantische Ethik und der Geist des Kapitalismus. München/Hamburg: Siebenstern Taschenbuch Verlag. 